\title{
Crítica para Educação Ambiental no Ensino de Geografia: aproximações teóricas
}

\author{
Critique for environmental education in geography teaching: \\ Theoretical approaches
}

\author{
Guilherme Pereira Cocato $^{1}$
}

\begin{abstract}
Resumo
Este estudo é movido por questionamentos teórico-metodológicos acerca das práticas e reflexões vigentes para a educação ambiental, inseridas no ensino de Geografia. Tais atividades pedagógicas são construídas em um viés crítico? O objetivo é investigar se a produção capitalista do espaço é considerada na compreensão dos processos de degradação sócio-ambiental em atividades pedagógicas desta temática. Adota-se a revisão bibliográfica do tema, por meio de abordagens teóricas amplas. Como método orientador, a crítica do materialismo histórico-dialético permeia e unifica as discussões da problemática ambiental, do ensino de Geografia, do papel dos docentes e do conceito essencial de análise: a produção do espaço capitalista. Portanto, a educação ambiental é discutida a partir de conceitos-chave do ensino geográfico, contrapondo-se práticas e propostas conservadoras e pouco elucidativas com alternativas didáticas possíveis de construção nos espaços pedagógicos. É essencial que as discussões realizadas se traduzam em práticas efetivas, a partir do enfoque pedagógico nos saberes cotidianos dos estudantes, complexificando-os para que, no retorno ao concreto, adquiram um caráter significativo na transformação sócio-ambiental.
\end{abstract}

Palavras-chave: Educação ambiental crítica. Ensino de Geografia. Modo de produção capitalista.

\begin{abstract}
This study is driven by theoretical and methodological questions about the current practices and reflections for environmental education, inserted in the teaching of Geography. Are such pedagogical activities built on a critical bias? The objective is to investigate if the capitalist production of space is considered in the understanding of the processes of socioenvironmental degradation in pedagogical activities of this theme. We adopt the bibliographic review of the subject through broad theoretical approaches. As a guiding method, the critique of historical-dialectical materialism permeates and unifies the discussions of the environmental problem, the teaching of Geography, the role of teachers and the essential concept of analysis: the production of capitalist space. Therefore, environmental education is discussed based on key concepts of geographical education, opposing conservative practices and proposals that are not very clear with possible didactic alternatives of construction in pedagogical spaces. It is essential that the discussions carried out
\end{abstract}

\footnotetext{
${ }^{1}$ Universidade Estadual de Londrina, Londrina, Paraná, Brasil. guilherme pereira@yahoo.com.br

Artigo recebido em: 22/01/2019. Aceito para publicação em: 10/06/2019.
} 
translate into effective practices, based on the pedagogical approach in the students' routine knowledge, making it complex, so that, in return they acquire a significant character in the socio-environmental transformation.

Keywords: Critical environmental education. Geography Teaching. Capitalist mode of production.

\section{Introdução}

As questões ambientais têm sido um amplo campo de debate tanto no ensino básico quanto no meio acadêmico, principalmente nos últimos 30 anos, com a escalada dos desastres ambientais, aliados aos avanços do meio técnico-científico-informacional; consequentemente influenciando as pesquisas em âmbito nacional e internacional. É uma temática cada vez mais emergencial, em um mundo de intensas transformações, pela vigência do atual modo de produção econômico. Por isso, recebe uma abordagem crítica, que realmente desafie a apropriação conservadora de conceitos e ações de cunho preservacional/ambientalista.

Partindo do questionamento para a forma como tais questões são trabalhadas, inclusive por atividades de cunho pedagógico pela chamada educação ambiental - mais especificamente em Geografia - elaborou-se a seguinte problemática: as atuais propostas de atividades pedagógicas para a educação ambiental, por meio do Ensino de Geografia, sob o viés crítico, consideram o contexto atual de produção do espaço capitalista?

Nesse sentido, no âmbito do ensino de Geografia, este estudo pode contribuir para o detalhamento e aprofundamento da crítica em relação às formas de abordagem da educação ambiental nos espaços pedagógicos.

Devido o envolvimento inerente da questão ambiental com os principais conceitos e temas da Ciência Geográfica, cabe a esta ciência assumir seu papel de protagonista nas mais diversas vertentes da educação ambiental. Pelo questionamento do que vem sendo desenvolvido nos crescentes espaços de debate nesta temática, procura-se dar uma nova possibilidade para a educação ambiental, que potencialize novas ações e 
enriqueça o ensino de Geografia como instrumento transformador e significativo na realidade dos educandos.

Com uma abordagem distinta da tradicional - a partir de embasamentos teórico-metodológicos significativos e questionadores - o objetivo deste estudo é discutir se as atuais atividades pedagógicas para a educação ambiental, no âmbito crítico do ensino de Geografia, consideram a realidade contemporânea de produção capitalista do espaço.

\section{Ciência Geográfica, Educação e Sociedade: aproximações teóricas} necessárias

Imprescindível para o início da discussão - ampla, ramificada e recheada de possibilidades - é a contextualização da temática ambiental atual no interior do ensino de Geografia, do modelo educacional vigente e consequentemente do modelo de sociedade que embasa a reprodução de tais discursos e práticas pedagógicas. No interior dessa discussão, partindo do paradigma moderno dominante, quais seriam as possibilidades para uma nova visão dos temas ambientais? Quais seriam os papéis e as responsabilidades do docente de Geografia e da própria Ciência Geográfica amparada pelo método crítico - na almejada transformação da educação tradicional, e, consequentemente, da sociedade que a criou?

A degradação sócio-ambiental globalizada impôs a necessidade às diversas disciplinas acadêmicas e científicas de se adequarem aos princípios ecológicos e ambientalistas dominantes em nossa sociedade (LEFF, 2007). Este almejado saber ambiental, que busca adentrar em todos os diferentes tipos de conhecimento, trata do mesmo ambiente atualmente dominado pela racionalidade econômica, técnica e científica da modernidade. Dessa maneira, é necessário construir uma nova racionalidade, desta vez ambiental, que leve em consideração os conhecimentos tradicionais e saberes histórico e culturalmente marginalizados e ignorados pelo método positivista e a ciência moderna. 
Para a transformação da racionalidade dominante em uma racionalidade ambiental, é essencial a perspectiva ideológica e política de sua concepção teórica e ações práticas. Esta postura crítica e subversiva para com a ordem vigente orientará construções epistemológicas e metodológicas, assim como o desenvolvimento técnico e social. Leff (2007) orienta que a problemática ambiental deve influenciar e ser influenciada por um conjunto complexo de conhecimentos e saberes verdadeiramente integrados entre as esferas social e ambiental.

A efetivação deste novo saber depende da postura em ações cotidianas, individuais e coletivas, dos sujeitos que almejam tal transformação, seja a partir de práticas pessoais ou profissionais/acadêmicas/docentes. O debate ambiental crítico pode ser fomentado em todos os espaços de construção social e política, principalmente no campo educacional. Este pode ser responsável por uma nova construção do conhecimento, democrático e próximo à realidade existente. Como aponta Porto-Gonçalves (2004), o debate (sócio)ambiental necessita de uma integração popular e emancipatória, com respeito aos mais diferentes modelos de sociedade.

Assim como a prática educativa - que possibilita uma dialética ao ser orientada pelo método tradicional, por nutrir caminhos pedagógicos libertadores que a transformam por dentro - o modo de vida orientado pelo viés econômico também possui suas contradições, e muitos outros modos de vida resistem em seu interior. São estas alternativas que se configuram como possibilidades concretas e podem ser fortalecidas. É o passo seguinte, após a tomada de consciência dos abusos que este sistema dominante impõe.

Determinante para a compreensão das condições sócio-espaciais cotidianas que determinam o ritmo da vida e as possibilidades econômicas a que os indivíduos se encontram presos pelo atual modo de produção, a educação, acredita-se, ainda é uma das formas de rebeldia para com a ordem estabelecida. Os instrumentos de transformação sócio-ambiental se 
conectam à diversidade teórico-metodológica trabalhada nos espaços pedagógicos e ao aprendizado de conteúdos significativos à realidade concreta, em que se insere, essencialmente, o ensino de Geografia.

Mészaros (2006) é um autor de destaque no fortalecimento da convicção dos que lutam contra o domínio do capital, a exploração e a opressão. Sua obra apresenta o debate acerca da possibilidade de superação da lógica do capital, por meio de processos educativos amplos, ou, em suas palavras, "no sentido genuíno e educacionalmente viável do termo" (p. 25). São indissociáveis as relações entre os processos educacionais e os processos sociais de manutenção da acumulação capitalista. Neste debate, é fundamental compreender que apenas uma ampla concepção de educação pode assegurar a luta pelo objetivo de mudança radical; e que o papel da educação é estratégico tanto para a mudança das condições de produção, quanto para a conscientização dos indivíduos envolvidos.

Romper com a lógica do capital no campo educacional representa, portanto, substituir formas e forças profundamente enraizadas por uma alternativa concreta possível no cotidiano das práticas pedagógicas. Depende da vontade e posicionamento do professor em compreender a realidade que o cerca e buscar demonstrá-la aos seus educandos. A educação, em seu entendimento amplo, é um processo contínuo de aprendizagem. "Temos de reivindicar uma educação plena para toda a vida, para que seja possível colocar em perspectiva a sua parte formal, a fim de instituir, também aí, uma reforma radical” (MÉSZAROS, 2008, p. 55). A reforma significa desafiar as formas dominantes no sistema educacional formal, cotidianamente, por meio da construção da autonomia tanto de discentes como dos docentes em sua prática educativa.

A posição aqui tomada não é de recusa ao ensino ou à ciência/progresso econômico, mas sim em busca de uma racionalidade nãotecnificada, que seria verdadeiramente racional. Um ensino que, privilegiando a construção do conhecimento crítico, considere a dimensão 
sócio-ambiental conjunta; e também considere as heranças específicas de uma construção histórica de mundo excludente, exploratória e gananciosa. Seria um grande passo na direção de uma abertura às outras possibilidades educacionais que parecem, na perspectiva deste estudo, mais adequadas aos desafios sócio-ambientais presentes.

Investigar as práticas pedagógicas significa refletir criticamente sobre o conteúdo a ser trabalhado, quais as maneiras para construí-lo coletivamente em um ambiente de aula diverso, e quais as fundamentações científicas, teóricas, práticas e ideológicas que melhor cabem em determinado contexto, para determinados objetivos. Aqui, se priorizam os objetivos que visam a reflexão para a transformação do modelo tradicional e descontextualizado, centrado somente na prática docente. Em uma escala mais ampla, busca-se a superação do atual modo de produção econômicopolítico, altamente prejudicial ao ambiente sócio-ambiental em todas as perspectivas imagináveis.

Segundo Souza (2011), do ponto de vista didático, o modelo de ensino tradicional em Geografia (e várias outras ciências) é centrado na consideração do conhecimento como verdade, que o professor domina e transmite aos discentes, em condição passiva. A descrição e a memorização se tornaram peças-chave, eliminando qualquer espaço de subjetividade ou análise crítica. Infelizmente, ainda são práticas didáticas muito presentes e difundidas.

Concorda-se com Souza (2011), quando se afirma que "o ensino eficaz é aquele que cumpre com a função escolar na formação do cidadão autônomo e crítico capaz de superar os problemas que afligem a sociedade atual" (p. 60). O papel do ensino de Geografia vai ao encontro deste propósito, pois só na compreensão espacial é que se pode entender a totalidade da lógica capitalista a que estamos submetidos. É preciso conhecer as diversas espacialidades do mundo, como locais de experiências individuais e coletivas, para também compreender que outras realidades são possíveis. 


\section{Da problemática ambiental à produção do espaço}

É por meio do entendimento dos fenômenos que influenciam na produção sócio-espacial da realidade cotidiana que se pode melhor compreender como agir sobre ela, inclusive acerca dos problemas de degradação ambiental. Dessa maneira, o ensino de Geografia e a educação ambiental são munidos de importantes ferramentas - partindo da realidade, se aprofundando na teoria, para depois retornar ao material - que serão repassadas às vidas dos educandos. O objetivo deixa de ser a abordagem pedagógica das problemáticas ambientais em termos quantitativos, para elevá-la de forma qualitativa inerentemente ao conceito fundamental de produção do espaço.

Modelos de sociedade anteriores ao modo capitalista de produção também possuíram formas de degradar as condições materiais de vida das quais necessitavam, por meio de práticas destrutivas e expansionistas. O geógrafo Élisée Reclus (1866), em seu texto "Du sentiment de la nature dans les sociétés modernes", já tratava sobre a violência ambiental presente ao longo da história humana, por sucessivas civilizações que derrubavam florestas, modificavam os cursos d'água, alteravam os climas e tornavam decadentes as condições de habitação nas cidades.

No entanto, existe uma ruptura entre as condições técnicas e materiais das sociedades anteriores e posteriores à Idade Moderna. Com as transformações históricas a partir das revoluções científicas e tecnológicas dos séculos XVII e XVIII, o modo de produção capitalista encontra sua possibilidade de existência e meios de reprodução ampliada, enquanto o conhecimento passa a ter seu principal sentido como "saber operatório" e de dominação da natureza (MARQUES FILHO, 2016, p. 592), com intensos reflexos na construção e no ensino das ciências. É assim que o meio natural passa a ser considerado distante da convivência social entre indivíduos humanos, e abrem-se as portas para o colapso ambiental iminente. 
Os dados contemporâneos acerca da degradação ambiental mundial são altamente conhecidos e amplamente divulgados. A existência da intensa exploração dos recursos naturais e poluição diversa pelos resíduos da atual produção econômica são incontestáveis, assim como os impactos sobre a saúde humana e todos os seres vivos do planeta. Como afirma PortoGonçalves (2004), nenhuma sociedade escapa à natureza, e esta deve ser cuidada como meio fundamental para a sobrevivência da espécie humana.

Dados do Instituto Homem e Meio Ambiente da Amazônia (IMAZON), aferidos a partir de imagens de satélite, apontam que, em março de 2018, o desmatamento na Floresta Amazônica já era 243\% maior do que no mesmo período do ano anterior. Concomitante a este processo, o plantio de soja em áreas desmatadas é o maior em cinco anos, crescendo 27,5\% em 2018, em relação à safra de 2017 (FONSECA et al., 2018). Estimativas indicam que por volta de 2030 , cerca de $27 \%$ da extensão original do bioma amazônico (em oito países) não terá mais árvores. Marques Filho (2016) utiliza dados do Global Land Degradation Assessment (GLADA) para afirmar que, atualmente, $42 \%$ das florestas estão sendo degradadas; e deve-se perder algo próximo de 170 milhões de hectares de florestas até 2030 . De 1800 a 2010 , foram 10 milhões de $\mathrm{km}^{2}$ de florestas erradicadas (MARQUES FILHO, 2016).

Atualmente, $33 \%$ dos solos do planeta estão de moderado a gravemente degradados, seja pela erosão, salinização, acidificação e/ou poluição química (MARQUES FILHO, 2016). A perda de solos produtivos prejudicará a produção de alimentos e influenciará nos preços praticados, tornando ainda maior a insegurança alimentar e a pobreza. "[...] a menos que se abandonem as práticas agropecuárias atuais, a quantidade de terra agricultável e produtiva em 2050 será apenas um quarto do nível de 1960" (MARQUES FILHO, 2016, p. 159). São $50 \mathrm{mil} \mathrm{km²}$ de solos agricultáveis perdidos anualmente, de acordo com este último autor; o que convém 
lembrar: são necessários em média 500 anos para se formarem dois centímetros de espessura de solo fértil.

Em relação ao aquecimento global, Marques Filho (2016) demonstra em sua vasta obra, Capitalismo e Colapso Ambiental, que 2015 foi o ano que marcou o aumento das temperaturas médias superficiais do planeta em $1^{\circ} \mathrm{C}$ comparativamente com a média dos anos 1850-1900. No hemisfério norte este aumento foi de $2^{\circ} \mathrm{C}$, para o mesmo período. Mantidas as emissões de gases de efeito estufa - que desde 2013 giram em torno de 32 gigatoneladas anuais, em números otimistas (MARQUES FILHO, 2016) - se alcançará uma temperatura média global $2^{\circ} \mathrm{C}$ acima das medidas do século XIX, já em 2036. Além disso;

[...] há mais. Estamos batendo recordes também de retração das geleiras de altitudes, de degradação dos solos, de escassez dos recursos hídricos (superficiais e subterrâneos), de acidificação, eutrofização e poluição por plástico dos oceanos, de elevação do nível do mar, de sobrepesca e de branqueamento de corais (MARQUES FILHO, 2016, p. 16).

Tais impactos sócio-ambientais estão diretamente relacionados com o desenvolvimento do comércio e modo de produção capitalista, e não se pode almejar abordá-los pedagogicamente somente de forma quantitativa, sem elucidar a essência de relações sociais e produtivas que tornam tais problemas ambientais urgentes. Almejando uma postura crítica em sala de aula, a abordagem de temáticas ambientais a partir do ensino de Geografia deve considerar, como é próprio desta ciência, múltiplas visões sócioespaciais, dialogando com diversas escalas de análise e possibilitando aos estudantes a visualização de tais questões no cotidiano, relacionando-as com o conhecimento científico sistematizado em dados e análises ambientais globais.

Pode-se afirmar que a questão ambiental reúne uma infinidade de princípios éticos e políticos, de acordo com a visão de mundo que se 
considere ideal, e não somente indica um caminho de soluções práticas. Tal debate, plural em possibilidades de transformação do atual modo de vida, pode ultrapassar as barreiras teóricas da produção acadêmica, alcançando a realidade escolar por meio da reestruturação de modelos didáticos comprometidos com o método crítico. Além de ações técnicas e imediatas, o debate aprofundado, envolvendo aspectos epistemológicos do ensino de geografia e educação ambiental, é essencial (CAVALCANTI, 2011).

Os problemas ambientais não possuem uma solução técnica absoluta, sendo este pensamento parte do problema a ser combatido no interior dos espaços de ensino e de aprendizagem. Segundo Porto-Gonçalves (2004), a crença inabalável no papel da técnica é fruto do ideário moderno-positivista, que também embasa o paradigma tradicional na educação. No intuito de modificá-la, procura-se ultrapassar esta superficialidade, assim como os fáceis termos de "desenvolvimento sustentável" e "sustentabilidade". O debate ambiental crítico passa pela superação dessa homogeneização dos estilos de vida e do modelo político-econômico atual. Também é necessária a consideração do sistema ambiental planetário como inscrito em um equilíbrio dinâmico de fluxos e trocas de matéria e energia.

Com o advento da modernidade e domínio da ciência pelo paradigma positivista-cientificista, a expansão do modo de produção capitalista se mascarou de missão civilizatória, absorvendo o genocídio, etnocídio e dominação/degradação do meio natural e povos tradicionais - bem assimilados a esse meio - assim justificando tais atrocidades (PORTOGONÇALVES, 2004). Fomentou a ideia de desenvolvimento baseado na exploração inconsequente de recursos naturais.

Ao se detalhar a tecnificação do debate ambiental, não se pode perder de vista que qualquer sistema técnico traz embutido a sua intencionalidade de criação e principalmente de uso. Uma crítica à técnica, portanto, é sempre uma crítica às intenções nela contidas. Como expoente em estudos a partir do método materialista que aprofundam a crítica da razão técnica- 
instrumental, Herbert Marcuse é citado por Marques Filho (2016, p. 597), em uma passagem indispensável para esta discussão:

O conceito de razão técnica é talvez também em si mesmo ideologia. Não só sua aplicação, mas já a própria técnica é dominação metódica, científica, calculada e calculante (sobre a natureza e sobre o homem). Determinados fins e interesses da dominação não são outorgados à técnica apenas "posteriormente" e a partir de fora - inserem-se já na própria construção do aparelho técnico.

Como exemplo, Porto-Gonçalves (2004) ilumina que para a dominação técnica da natureza, deve-se dominar igualmente a sociedade, para fazê-la acreditar em tais ações. Tudo isso é colocado em prática por sistemas intelectuais e pedagógicos, para que as relações modernas de dominação possam crescer e se desenvolver.

Assim, des-envolver é tirar o envolvimento (a autonomia) que cada cultura e cada povo mantém com seu espaço, com seu território; é subverter o modo como cada povo mantém suas próprias relações de homens (e mulheres) entre si e destas com a natureza; é não só separar os homens (e mulheres) da natureza como, também, separa-los entre si, individualizando-os (PORTO-GONÇALVES, 2004, p. 39).

Dessa maneira, a crítica do paradigma técnico-cientificista é igualmente a crítica ao modelo tradicional de ensino, ao esvaziamento/distanciamento de significados dos conteúdos e à postura opressora do docente em sala de aula. Todos elementos que refletem a dialética entre as relações sócio-produtivas vigentes na sociedade atual e as práticas educacionais tradicionais que nela se perpetuam.

As relações de poder se transformaram a partir da tecnologia e da ciência, como também podem se transformar mais uma vez. Como afirma Porto-Gonçalves (2004), não existe relação com a natureza sem significações socialmente construídas, que podem ser re-significadas dentro de contextos 
históricos e geográficos diferenciados. Whitacker (2013) entende que a discussão acerca das relações sociedade-natureza, atualmente, resultam em considerações simplistas e ineficientes, o que remete à necessidade de uma retomada de tais debates a partir da base social, nos ambientes de moradia, trabalho e educação.

É papel do conhecimento crítico elucidar estes processos, propondo novas formas de intervenção e compreensão do panorama sócio-ambiental mundial, evidenciando a fragmentação da ciência positivista que não questiona as razões por detrás de determinados progressos técnicos e científicos. Assim como elucidar conceitos e termos aparentemente revestidos de cunho ambiental, que devem ser estudados mais a fundo e desmistificados, se preciso.

Um destes termos é o "desenvolvimento sustentável", protagonista para o ambientalismo contemporâneo, em diversas vertentes. A sua reprodução, sem o devido discernimento crítico da essência ideológica/epistemológica presente, pode levar à reprodução de um termo verdadeiramente conservador e aliado à perpetuação da exploração ambiental massiva.

Tal debate torna-se crucial para o ensino de Geografia e seus docentes, responsáveis por fomentar atividades pedagógicas que possam ir além da racionalidade dominante, reproduzida constantemente no cotidiano dos educandos. Acredita-se que o rótulo de sustentável é somente mais um afixado ao conceito tradicional de desenvolvimento. A dialética da questão ambiental produziu o seu oposto, o discurso neoliberal de sustentabilidade, que prega a aliança entre meio ambiente e desenvolvimento pelos mecanismos de mercado, que supostamente podem incorporar os valores ambientais. O desenvolvimento sustentável, portanto, é apropriado para a lógica empresarial, inerente ao próprio conceito (MONTIBELLER, 2004).

Seus princípios polissêmicos foram aceitos sem maiores questionamentos, e amplamente disseminados em diversos espaços 
pedagógicos de ensino de Geografia, por meio de ideias ligadas à "conservação" ambiental. Justamente por abarcarem, de maneira vaga, desejos universais e pouco formulados de crescimento econômico para todos, melhores condições de vida e igualdade social. Neste contexto, pouco ou nada influenciam nas relações de exploração, incapazes de questionar o status quo, já que são criados por ele. Mas, simultaneamente, o discurso ambientalista do medo é difundido, culpabilizando as pessoas na escala individual e pouco impactante, já que não se organizam coletivamente.

De acordo com o método materialista histórico-dialético, percebe-se uma forma de controle social exercido pela ideologia do mercado, efetivado nos espaços educacionais, que afasta as sociedades da natureza (WHITACKER, 2013). Pode-se considerar esta ideologia como presente em todas as relações de poder efetuadas pelos interesses dominantes e perpetuadas por sua classe:

As ideias (Gedanken) da classe dominante são, em cada época, as ideias dominantes; isto é, a classe que é a força material dominante da sociedade é, ao mesmo tempo sua força espiritual dominante. A classe que tem à sua disposição os meios de produção material dispõe, ao mesmo tempo, dos meios de produção espiritual (MARX e ENGELS, 2005, p. 78).

Este "trabalho" ideológico é feito no sentido de manter a organização social desigualmente baseada na exploração social e degradação ambiental. Segundo Oliveira (1999), para isso assume-se uma função de negatividade ou de ilusão, provocando uma falsa consciência geral sobre os indivíduos. Já Chauí (1982) afirma que a maior intenção da ideologia é ocultar as formas da realidade, tomando as ideias dominantes como verdades inquestionáveis. Para isso, é feito tanto o controle das condições materiais quanto imateriais. Um dos exemplos de condição imaterial fundamental para a formação dos ideais e posturas que moldam a sociedade contemporânea é a ciência e seu 
ensino, que devem ser considerados como campos de embate essenciais no almejo de transformações sócio-ambientais concretas.

Segundo Bourdieu (2010), a ideologia é reproduzida pelo poder simbólico das palavras, que, organizadas em forma de discursos bem articulados, se disseminam, carregados de intenções. As palavras cumprem seu papel de imposição ou legitimação da dominação, corroborando o domínio de alguns indivíduos sobre os demais. De acordo com este autor, pode ser considerada como um tipo de violência - a simbólica - que embasa a desigualdade pela submissão. Inclusive, pode ser melhor perpetuada por meio do modelo de ensino tradicional, no qual o professor é considerado como detentor do conhecimento a ser repassado aos estudantes mantidos em estado passivo.

Não é por coincidência que o discurso ideológico do desenvolvimento sustentável é reproduzido globalmente, em espaços pedagógicos, comerciais e de lazer, já que a economia capitalista também é mundial e dominante (principalmente em sua escala financeira). Indo mais longe, Foucault (2001) nos diz que toda sociedade controla e seleciona o que pode ou não ser dito em uma determinada época. Assim se delimitam os discursos social e economicamente aceitos, e afastados os que são possivelmente subversivos à ordem vigente. As relações de poder estão intrinsecamente embutidas nestes discursos: "[...] não há relação de poder sem constituição correlativa de um campo de saber, nem saber que não suponha e não constitua ao mesmo tempo relações de poder" (FOUCAULT, 2001, p. 72).

Aparecem, portanto, todas as limitações e contradições de um discurso como o do desenvolvimento sustentável, quando exercido em sociedades orientadas pelo mercado. As vulnerabilidades existem, assim como são ínfimas as chances de concretização de seus princípios. A própria polissemia do termo contribui, simultânea e paradoxalmente, para sua aceitação e questionamentos em relação às suas verdadeiras origens e finalidades. Esse 
é o verdadeiro espírito de uma educação ambiental de cunho crítico, que se procura enfatizar urgentemente em todas as práticas pedagógicas.

\begin{abstract}
A evidente ênfase dada aos aspectos econômicos e tecnológicos das questões relativas ao meio natural também contradiz as promessas de uma abordagem plural e complexa de desenvolvimento; sugere, ainda, o predomínio da esfera do mercado na condução da ideia de desenvolvimento sustentável em detrimento da sociedade civil e do Estado. Para os setores interessados num projeto de mudanças de maior amplitude, esse desenvolvimento sustentável de mercado, que tem orientado as ações e debates recentes, denuncia a falácia dessa ideologia e seu discurso (WHITACKER, 2013, p. 86).
\end{abstract}

Segundo Whitacker (2013), sem o debate estrutural sobre as bases deste sistema, dificilmente será possível o avanço efetivo na temática ambiental, principalmente nas lacunas em considerar a realidade dos educandos e suas necessidades concretas de compreensão acerca das verdadeiras motivações de perpetuação das relações de dominação e exploração, impressas nas formas e práticas sócio-ambientais cotidianas. São os mecanismos de dominação que descaracterizam a realidade e impõem relações de produção desiguais - inclusive do espaço - como universais.

Apesar de algumas temáticas e autores constituírem elementos complexos para uma abordagem reduzida em sala de aula, grandes ideias podem ser construídas e materializadas em atividades pedagógicas aplicáveis no ambito da educação ambiental. A partir de conceitos-chave para a Geografia, podem-se realizar diversas transições e correlações entre os conteúdos curriculares, os problemas sócio-ambientais atuais e o método crítico de construção do conhecimento; representado pelos princípios orientadores do materialismo dialético que exerce influência no conceito de produção do espaço.

Como afirma Lefèbvre (2000), é papel da crítica do espaço questionar quais são as relações sociais sacrificadas em prol da exploração e degradação do meio natural e da produção de espaços artificiais e opressores. Neste 
sentido, as necessidades básicas de reprodução do atual modo de produção sócio-econômico também são as orientadoras e impulsionadoras de drásticas modificações dos espaços geográficos, tornando o próprio modo de produção capitalista um dos temas inevitáveis para a pesquisa e discussão.

Não percebendo a verdadeira essência na produção dos espaços capitalistas, acabamos vendo a realidade sem concebê-la. O sistema vigente nos repassa a ideia de um espaço "neutro", "objetivo", enquanto a questão ambiental é mascarada e envolvida por um debate insuficiente e alienado, recheado de interesses particulares. Conceitos como "sustentabilidade" e "ecodesenvolvimento" podem ser considerados como um conjunto de ilusões. Possuem uma utilidade limitada e questionável próximos à realidade da qual são postos como soluções. Tais discursos são conservadores e não buscam a transformação da ordem vigente. Funcionam como desvios da crítica do espaço, e "substituem a análise crítica por esquemas ao mesmo tempo pouco racionais e muito reacionários" (LEFÈBVRE, 2000, p. 86).

Os espaços passam a ser comercializáveis, quantificados pelo seu correspondente em dinheiro. É mais um produto que pode ser produzido repetidamente em diferentes localidades. Todas as sociedades humanas construíram seu espaço gradualmente ao longo de sua existência, mas o modo de produção pautado na racionalidade técnica o produz de maneira acelerada, sem precedentes ou consideração por outras formas de vida e pela própria espécie. E, como qualquer outra mercadoria, o espaço oculta suas intenções de formação. Os valores de troca tornam-se a palavra final em um planeta-mercadoria, em que produzir é, acima de tudo, produzir espaço (LEFÈBVRE, 2000).

$\mathrm{Na}$ produção de seu espaço, o capitalismo se baseia na propriedade privada dos meios de produção, em uma estrutura social que não se apoia somente nos instrumentos ou máquinas utilizadas, mas sim na exploração da força de trabalho e das relações de produção. É a partir do processo de produção do espaço, enquanto prática do capitalismo, que Smith (1988) 
elaborou sua concepção de desenvolvimento desigual. Ele critica os que consideram este processo desigual de produzir espaço como "uma lei universal da história humana", pois desta forma assume um caráter metafísico, com o seu significado reduzido a um mínimo denominador comum.

Lefèbvre (2000) fundamenta a importância com que o modo de produção capitalista realmente produz a concretude atual, móvel e imóvel, (re)organizando o espaço à sua maneira e a partir dos seus interesses de acúmulo e reprodução. A busca pelo lucro torna-se cada vez mais voraz, irracional e degradante para a sobrevivência de todos os seres vivos do planeta e a complexa dinâmica de seus sistemas integrados.

A degradação ambiental mostra-se totalmente imbricada na lógica de (re)produção do espaço, como processo inerente a ela. Justamente por isso, ao questionar as práticas de educação ambiental vigentes, e de tratamento da questão ambiental como todo, não se pode trabalhar de forma isolada ou reducionista.

As possibilidades de mudança quanto à degradação ambiental ficam restritas quando não consideram o funcionamento do atual modo de produção, justamente por não considerarem o cerne do problema e terem alcance limitado pelas relações de poder vigentes. A verdadeira questão é a impossibilidade de se adequar a reprodução capitalista com o desenvolvimento sustentável. Para isto, a consideração de um espaço ambiental transnacional e transescalar é imprescindível, ideia esta a ser construída no plano material e imaterial das salas de aula, em conjunto com os estudantes e por meio de suas experiências concretas e exemplos cotidianos.

De todas as fontes provém a mesma mensagem: o colapso ambiental é inevitável, se o atual modelo de produção e (des)envolvimento perdurar. Isto só eleva a importância do estudo ambiental a partir de uma abordagem abrangente que considere a totalidade de maneira crítica, que perceba os 
impactos em escala local associados com os movimentos amplos do capital, e busque alternativas em prol de relações sócio-produtivas mais toleráveis; a começar pelos ambientes de ensino e de aprendizagem. As práticas educacionais ambientais, e consequentemente o ensino de Geografia, podem assumir importantes papéis nesta discussão.

Entende-se que o movimento mais urgente é a união das pautas e reivindicações sociais e naturais, que essencialmente nunca estiveram separados. Como afirma Marques Filho (2016, p. 670), “[...] hoje, o programa político é lutar por uma sociedade capaz de voltar a caber na biosfera”. Esta é uma ideia revolucionária, condizente com todas as tentativas de ruptura sócio-econômica ao longo dos últimos dois séculos. Para reverter o problemático quadro ambiental, é preciso recorrer também às revoluções econômicas, sociais, políticas, ideológicas e principalmente educacionais. No momento de maior urgência, reforça-se a esperança de que tais movimentos são possíveis. Neste sentido, Löwy (2013, p. 19) nos aprecia com o pensamento de Walter Benjamin:

Marx havia dito que as revoluções são a locomotiva da história mundial. Mas talvez as coisas se apresentem de maneira completamente diferente. É possível que as revoluções sejam o ato, pela humanidade que viaja nesse trem, de puxar os freios de emergência.

A construção gradual de um imaginário emancipador, tanto individual como coletivo, é melhor alcançado pelo avanço do raciocínio crítico nos espaços pedagógicos, que podem oferecer a oportunidade de melhor conexão entre os conteúdos abstratos e a realidade concreta. Amplia-se assim o conhecimento significativo a ser utilizado pelos educandos ao longo de suas vidas, e, a partir do método crítico, dão-se condições de compreender, questionar e possivelmente transformar as condições sócioambientais de seus espaços de vivência. 


\section{Considerações Finais}

Ao longo do trabalho, foram realizadas discussões entre autores e correntes de pensamento pertinentes ao tema e ao método escolhido. Neste contexto, destaca-se a importância do método crítico como motivador e orientador de transformações sócio-espaciais, abstratas e concretas; da Ciência Geográfica como campo de ensino, pesquisa e atuação nas temáticas ambientais; e, finalmente, o papel do docente, que por meio de postura engajada e combativa, pode modificar as atividades pedagógicas, tornandoas mais significativas ao aproximá-las dos discentes e relacioná-las com suas experiências.

O movimento de - não somente informar acerca das desigualdades e degradações sócio-ambientais, mas contextualizá-las frente ao paradigma moderno da ciência e da técnica, do sistema capitalista e suas formas de produção do espaço - foi um dos elementos principais da discussão teórica. O enfoque dado às evidências do colapso ambiental contemporâneo e de suas principais causas por meio da compreensão de funcionamento do modo capitalista de produção torna-se fundamental para o ambiente acadêmico e escolar, desafiando e impulsionando os professores à construção do conhecimento integrado, próximo ao concreto e questionador. Para isso, a educação ambiental abordada nas aulas de Geografia é essencial, assim como a busca de transformações teórico-práticas nesta temática se associam diretamente às mudanças de paradigma do ensino tradicional ainda vigente.

Trazendo à tona a problemática motivadora do trabalho, considera-se que esta pode ser respondida de forma precisa, de acordo com a investigação teórico-metodológica apresentada. Atualmente, encontram-se inúmeras limitações ao pensamento e práticas da educação ambiental vigente ou tradicional. São atividades que desconsideram e impossibilitam o questionamento a fundo dos processos causadores da degradação e desigualdade sócio-ambiental, ligados à produção, acumulação e consumo 
capitalistas. Dessa forma, exercem o papel de conservadoras da ordem vigente, culpabilizando práticas individuais e desconsiderando as relações sócio-produtivas e a dominação econômica como todo, que influenciam diretamente na produção de espaços insustentáveis e degradados.

Neste sentido, entende-se que por não serem significativas às transformações almejadas - apesar de se considerarem como tal - as práticas da educação ambiental vigente necessitam de outras abordagens, que atualmente acontecem de maneira esporádica. Pelos espaços de degradação - e possivelmente de transformação - serem objeto de estudo da Geografia, o ensino desta ciência pode dar um passo a frente e assumir para si as discussões acadêmicas e práticas escolares tão urgentes no âmbito sócio-ambiental. Para isso, os docentes e acadêmicos necessitam de aprofundamento nesta questão, fomentando mais estudos e consequentemente a prática, sempre orientada à construção crítica dos conhecimentos.

\section{Referências}

BOURDIEU, P. O poder simbólico. São Paulo: Bertrand Brasil, 2010.

CAVALCANTI, L. de S. Ensinar Geografia para a autonomia do pensamento: O desafio de superar dualismos pelo pensamento teórico crítico. Revista da ANPEGE, Dourados, v. 7, n. $1, \quad \mathrm{n}^{\circ}$ especial, p. 193-203, 2011. Disponível em: <http://ojs.ufgd.edu.br/index.php/anpege/article/view/6563>. Acesso em: 20 abr. 2018. https://doi.org/10.5418/RA2011.0701.0016

CHAUÍ, M. O que é ideologia. São Paulo: Brasiliense, 1982.

FONSECA, A. et al. Boletim do desmatamento da Amazônia Legal (março de 2018). Belém: IMAZON, 2018. Disponível em: <http://imazon.org.br/publicacoes/boletim-dodesmatamento-da-amazonia-legal-marco-2018-sad/>. Acesso em: 29 de jun. 2018.

FOUCAULT, M. A ordem do discurso. São Paulo: Loyola, 2001.

LEFÈBVRE, H. A produção do espaço. Tradução de Doralice Barros Pereira e Sérgio Martins. 4. ed. Paris: Éditions Anthropos, 2000. Tradução de: La production de l'espace.

LEFF, E. Saber ambiental: do conhecimento interdisciplinar ao diálogo de saberes. In: LEFF, E. Epistemologia ambiental. 4. ed. São Paulo: Cortez, 2007. p. 151-190.

LÖWY, M. Introdução a Walter Benjamin: O capitalismo como religião. São Paulo: Boitempo, 2013.

MARQUES FILHO, L. C. Capitalismo e colapso ambiental. 2. ed. Campinas: Editora da Unicamp, 2016.

MARX, K.; ENGELS, F. A ideologia alemã. São Paulo: Martin Claret, 2005.

MÉSZAROS, I. A educação para além do capital. Coleção Mundo do Trabalho. São Paulo: Boitempo, 2006. 
MONTIBELLER, G. F. O mito do desenvolvimento sustentável: meio ambiente e custos sociais no moderno sistema produtor de mercadorias. 3. ed. Florianópolis: Editora UFSC, 2004.

OLIVEIRA, V. M. de. Ideologia: atualizando a reflexão. Concinnitas, Rio de Janeiro, v. 1, p. 145-153, 1999.

PORTO-GONÇALVES, C. W. O desafio ambiental. Rio de Janeiro: Editora Record, 2004.

RECLUS, E. Du sentiment de la nature dans les sociétés modernes. Revue des Deux Mondes, [S. 1.], n. 63, p. 352-381, 1866.

SMITH, N. Desenvolvimento desigual. Rio de Janeiro: Bertrand, 1988.

SOUZA, V. C. de. Fundamentos teóricos, epistemológicos e didáticos no ensino da Geografia: bases para formação do pensamento espacial crítico. Revista Brasileira de Educação em Geografia, Rio de Janeiro, v. 1, n. 1, p. 47-67, 2011. Disponível em: $<$ http://www.revistaedugeo.com.br/ojs/index.php/revistaedugeo/article/view/15>. Acesso em: 13 mar. 2018.

WHITACKER, G. M. Sobre o discurso ideológico do desenvolvimento sustentável e a reprodução do modo capitalista de produção. Boletim Goiano de Geografia, Goiânia, v. 33, n. $1, \quad$ p. 73-89, jan./abr. 2013. Disponível em: <https://revistas.ufg.br/bgg/article/view/23633>. Acesso em: 12 mar. 2018. https://doi.org/10.5216/bgg.v33i1.23633 